Special Article

\title{
Hahnemann and the methodology of pathogenetic trials in healthy volunteers: a reappraisal.
}

\author{
Jim Rogers \\ University of Lincoln, United Kingdom
}

\begin{abstract}
This article assesses the guidelines and protocols that Hahnemann developed for homeopathic pathogenetic trials (HPTs) - often referred to as proving - and reappraise them in the light of more recent knowledge and protocols for clinical trials involving human subjects. Innovative features and methods introduced by Hahnemann and aimed at reducing bias are noted. A number of features which are now known to lead to bias in trials and which may be included in the reporting of symptoms are discussed in relation to HPTs. These features include: absence of control groups, absence of random allocation, absence of blinding, the inclusion of trivial and preexisting symptoms, the inclusion of well-known acquaintances as trial participants, and the lack of definition of the healthy state. Advice from experts and papers published in recent decades related to the design of HPTs are discussed. The importance of developing methods to screen participants in HPTs for susceptibility to the tested medicine is discussed. The absence of trials meeting high quality standards in their design is highlighted. The article concludes with a plea for researchers to show the same desire for rigour and innovation that Hahnemann did in the development of HPTs, whilst fully recognising the requirements and protocols necessary for any trial of medicines on human beings, so that, as Hahnemann wanted, only reliable symptoms from HPTs will be admitted in the materia medica and clinical practice.
\end{abstract}

Keywords: Homeopathy; Pathogenetic trials; Phase 1 clinical trials.

\section{Introduction}

Homeopathic pathogenetic trials (HPTs) remain one of cornerstones of the knowledge grounding homeopathic practice together with data arising from clinical experience and toxicology. As such it is essential that they are conducted in a manner producing reliable information. In this article I aim to critically assess the methodology of HPTs focusing on the instructions supplied by Hahnemann and subsequent authors, analysing them in the light of what was known about drug trials at that time and what is known now.

The path that led Hahnemann to enunciate the principle of experimentation on the healthy as the proper means to discover the therapeutic properties of drugs began in 1790, with his self-experimentation of Peruvian bark, reported as a footnote to his commented translation of William Cullen's Lectures on the Materia Medica [1].

After putting his developing ideas about the testing of medicines into practice for several years, in 1805 he published, in Latin, a book whose title translates as 'Fragments on the Positive Powers of Medicines as Observed on the Healthy Human Body' [2]. Later that same year he published an essay, 'The Medicine of Experience', where he first laid down instructions for the methodology of HPTs.

Hahnemann went on to express his developing ideas in successive editions of the Organon of Medicine from the first edition in 1810 to the sixth and final edition, which was completed in 1842 (although it was not 
published until1921). During this evolution of his thinking some of the instructions to conduct HPTs remained constant, while others changed significantly.

One point on which Hahnemann changed his view over time was in relation to the dilutions to be used. He began with crude substances (as in the original Peruvian bark experiment) and went on to test many substances in low dilutions. In the sixth edition of the Organon he recommends "daily doses, for several days, of four to six very fine granules of the $30^{\text {th }}$ potency of the substance we wish to test" [3].

In 1811 he took up a post as lecturer at the University of Leipzig. Opting for what might be considered to be a very modern view of learning, he suggested that his students should be active rather than passive learners and he organised some of his students into a group of collaborators to test drugs. They became keen experimenters and went on to carefully test a wide range of substances. The results of these extensive experiments were published in the Materia Medica Pura, which was published in six parts between 1811 and 1821 [4]. It remains unclear in most cases what dilutions were used in the HPTs carried out in this period, but some are described in Materia Medica Pura. Thus we know that, just among the mineral remedies, everything from crude substance (Calcarea acetica), to 3c (Carbo vegetabilis), 15C (Argentum nitricum) and 30c (Natrum muriaticum) was used.

As a whole, Hahnemann was involved in over $100 \mathrm{HPTs}$, using what would be recognised today as quasiexperimental designs [5]. In the 200 years since the first of such experiments the homeopathic community conducted many further original HPTs and re-trials of previously tested medicines.

We know that Hahnemann built on the work of many $18^{\text {th }}$ century researchers into self-experimentation and experimentation on the healthy [6]. In his 1796 'Essay on a new principle for ascertaining the curative powers of drugs' Hahnemann developed this idea and introduced the notion of ascertaining more specific and subjective symptoms from such experiments rather than generalised ones - what Tischner called "the passage from the 'unspecific' to the 'specific' simile" [7].

Hahnemann was innovative in the way that he developed the methodology of HPTs. To try to minimise bias he recommended that only conscientious and trustworthy volunteers who were healthy at the time of the trial should take part. On the other hand, that medicines should be tested single and in pure form with close supervision of subjects throughout the duration of the trial.

Hahnemann recommended quite strict rules to control what he believed to be important confounding variables. His aim was to ensure a constant steady state in which any changes caused by the medicine would be easier to detect, he therefore recommended that the consumption of tea, coffee, alcohol, medicines, herbs and spices and any foods which might have medicinal effects should be avoided.

Hahnemann was convinced that medicine needed to progress via clinical experiment rather than by theoretical debate. He was very concerned with the reliability and validity of drug trials, as can be seen in the Organon, note to $\$ 139$ "anybody publishing the results of such experiments for the medical world becomes responsible for the reliability of the experimental subject and the accuracy of his reports, and rightly so, since the well being of suffering mankind is at stake" [4, p.116]. Hahnemann was well aware of the dangers of suggestion and some of the ways in which bias and unreliable information might undermine the usefulness of HPTs. He adopted a number of measures to reduce bias that were innovative for the early to mid $19^{\text {th }}$ century, although from the perspective of the current understanding of human behaviour his measures were not sufficient to control some major sources of potential bias.

Flaws in the instructions developed by Hahnemann 
After Hahnemann, there was little change in the generally accepted methodology of HPTs until relatively recently. This is unfortunate since, despite the care he took, there are significant flaws in later HPTs. In a key article, Dantas listed a number of these flaws and suggested the reasons why some of Hahnemann's design features may lead to an overestimation of pathogenetic effects [8].

\section{Attributing all symptoms occurring during a HPT to the medicine.}

Already in the $19^{\text {th }}$ century, authors such as Dudgeon recognised the flaw in this idea. Dudgeon says:

"It can hardly fail to strike us that there is another point connected with Hahnemann's directions for provings, which we cannot regard as a very reliable source for ascertaining the virtues of medicines, and that is his statement that 'all the phenomena that arise during the action of a medicine are solely derived from this medicine and must be registered as its symptoms even though some of these may be such as he had noticed previously as occurring spontaneously.' I am sorry that Hahnemann should have allowed this to be a pure source for I fear it has opened a door for the admission into the materia medica of many symptoms that have no business there." [9]

The following discussion elaborates on some of the ways in which symptoms that are not genuine pathogenetic effects may end up being recorded as such.

\section{The absence of a control group as standard.}

There continues to be a legitimate debate about the best research designs for homeopathic trials [10]. However, it is important to understand the key features of standard medical and pharmacological trials and to understand the reasons for these features, most of which aim at minimising different kinds of bias. A control group is a very useful and widely used method of reducing bias.

There are several features which introduce bias into trials that do not use control groups. These include temporal effects, which simply refer to the fact that people change over time regardless of any intervention. In relation to HPTs, those who are healthy at the beginning of a trial may very well develop a whole range of symptoms during that trial that would have happened anyway and are not linked to the remedy being tested. A number of studies have shown that many symptoms occur spontaneously in daily life even in the most apparently healthy groups of individuals, with up to a third of individuals reporting six or more symptoms in a 3 day period [11].

Observer expectancy effects are well known in social science [12]. People tend to see what they want to see or expect to see. Assessors and participants in HPTs are usually homeopaths and are likely to be predisposed to expect new symptoms to occur during such trials.

Symptoms recorded as new or different during the course of HPTs may be partly or entirely due to temporal effects, factors relating to selection and recruitment of participants, observer expectancy effects and other potential sources of bias. One useful way to determine whether effects are really caused by the remedy is to see whether they are qualitatively and quantitatively different in a group receiving the remedy in comparison to a control group not receiving the remedy. Alternatively researchers have also developed methodologies in which the participant forms his or her own control at different points of the trial.

Some argue that the way to test whether symptoms are due to real pathogenetic effects is to see whether they can subsequently be successfully treated in clinical practice. Whilst this might provide additional verification it is simply postponing the problem [13]. Such an approach requires a number of years and the cumulative experience of a number of practitioners before a definite judgement can be made about the reliability of symptoms. On the other hand, pathogenetic trials ought to be methodologically sound so as to supply by themselves reliable information on actual drug effects and other factors including placebo. 


\section{The absence of random allocation.}

If it is accepted that control groups are essential for detecting real differences attributable to an intervention, then it is important to ensure that the control and the intervention groups are as similar as possible. It is widely accepted in the health sciences that random allocation is the only way to ensure this. Indeed some argue that "random allocation is the essence of the RCT" [14]. Randomisation is by far the best way of controlling temporal changes, regression to the mean, and selection bias (selecting people who are different on some measures at the start and who are therefore likely to show different outcomes). There is good evidence that non randomised trials yield consistently larger estimates of treatment effects than the randomised ones [15], although other studies have cast some doubts on this, and there remains uncertainty about the magnitude of any differences [16].

\section{The absence of blinding.}

Trials that do not use blinding tend to show larger treatment effects than those that do [17]. This is not surprising. Unless both participants and investigators are blinded as to who is receiving the active intervention, people will react in ways which are biased towards a particular favoured outcome.

The use of control groups and blinding are central features of modern pharmacological trials. Whilst these were not requirements in Hahnemann's times, they were introduced by later homeopathic researchers, and indeed, it can be claimed that they were significant innovations in these areas. As Dantas et al have noted [18], the first blinded placebo controlled HPT took place in a naval hospital in St Petersburg in 1834, and a year later a double blind trial was carried out in Nuremberg, which even attempted random allocation [19]. One of the first multicentre double-blind clinical trials known to medicine took place when Bellows coordinated a HPT of Belladonna (mostly using mother tincture) in 11 centres in the USA [20].

\section{The inclusion of trivial and pre-existing symptoms.}

In order to find the pathogenetic effects that may be produced by a remedy in HPTs close observation is certainly necessary. Such effects may be rare, subtle, and short lived, and will only be recorded if the volunteer applies careful attention and has good supervision. However, the daily and detailed recording which takes place in HPTs is highly likely to lead to the inclusion of many naturally occurring and pre-existing symptoms that a person becomes aware of because of the unusually close monitoring of the body and self required for the trial.

Hawthorne effects refer to the tendency for people to change their behaviour when receiving the kind of special interest and attention which occurs when they are part of a trial. Hawthorne effects are known to be a significant non specific effect of participation in trials [21], and the kind of close scrutiny which takes place in HPTs is only likely to increase this phenomenon.

Again, the use of a control group receiving an identical placebo intervention will help to control Hawthorne effects by ensuring that they are spread equally between the two groups.

\section{Lack of definition of the healthy state.}

Hahnemann grappled with this idea and admitted that health is relative, for instance, when he stated in Organon $\S 126$ that the participant must be "in what is for him a good state of health" [3, p.110].

Whilst it has become a platitude that only healthy volunteers should be enlisted in HPTs, remarkably very few authors have defined what is meant by "healthy", or actually measured it in some way. From extensive health-related research it is known that even the healthiest among people experience day-to-day fluctuations in symptoms, and over the course of a trial these may give rise to significant background noise. Therefore, 
without careful checks and definitions of health, it is likely that some pre-existing symptoms of illness will be recorded as proving symptoms.

Kaptchuk [13] has highlighted some studies that illustrate the size and variability of this background noise. In one study, 414 individuals who worked or studied at a university medical centre were healthy in the sense of reporting no current illness and no medication use in the previous 3 days. From this sample, $81 \%$ had at least one symptom in the previous 72 hours based on a 25 symptom adverse event questionnaire [22]. Kaptchuk notes that the symptom checklist looked very much like the tabulated results of an HPT.

\section{The use of well known acquaintances as volunteers.}

There are good arguments for having volunteers in HPT's who have an understanding of homeopathy. They may be more likely to record the type of symptoms that are useful in homeopathic terms [23]. It is perhaps for this reason that Hahnemann suggested in $\S 141$ of the Organon that experiments "which the sensitive physician experiences on himself" are the best of all [3, p.117]. However, it is also the case that placebo effects are heightened in trials in which participants have strong expectations and, for example, believe strongly in the intervention on trial [24].

\section{The sudden prohibition of all medicinal drugs and foodstuffs.}

We know that Hahnemann was very specific in this matter. However, we should be aware that an unintended consequence might be that volunteers who suddenly abstain at the start of a trial from what may be frequently consumed substances, may experience withdrawal symptoms and abstinence effects, and that such symptoms may be wrongly attributed to pathogenetic effects of the remedy.

\section{Susceptibility and HPTs}

Whilst all of the above are likely to lead to an overestimation of pathogenetic effects, there is a significant factor which is likely to lead to under reporting of pathogenetic effects in most HPTs. This is the issue of susceptibility, which is a fundamental principle of homeopathic practice. A principle of homeopathic clinical practice is that only remedies the patient is susceptible to will accomplish therapeutic effects and this must also be taken into account when conducting HPTs.

In HPTs a crude dose may have material or toxic effects on all participants, but diluted, the particular remedy will only affect those who are susceptible to it. Herscu has shown clearly how the same principles should be applied to both clinical practice and HPTs and concurs that susceptibility is highly important: "the thinking process about the predisposition of the prover has not been addressed in our profession, but clearly must be"[25].

However, it is very rare to find a HPT which screens volunteers for susceptibility before recruiting them into the trial. This could be added to the study protocol by dividing it in two stages. In the first one a large number of participants would be recruited for a trial using low dilutions of a drug. Those showing distinct proving reactions would be recruited for the second stage, where they would be randomly allocated to either further testing of the drug or placebo. The percentage of participants who are actually susceptible will vary according to the dilution used and other factors. Proving rates average just $13 \%$ of participants in trials that use typical $30 \mathrm{cH}$ dilutions [26].

In the Organon, Hahnemann acknowledged this issue in relation to HPTs. He stated that strong medicines would bring about alterations in health, even to "robust people". He then suggested that "weaker ones", on the other hand, "reveal their true action only when tested on delicate susceptible and sensitive people" [3, p.108]. 
Many reports of HPTs suggest that all the symptoms which occurred in those HPTs are attributable to real pathogenetic effects, and none to other factors. Also many reports of HPTs suggest that all volunteers who take part do experience pathogenetic symptoms. A proper awareness of susceptibility should lead us to be sceptical of such claims. Dantas et al illustrated in their review that those trials which claimed pathogenetic effects in all volunteers tended to be of the lowest methodological quality, suggesting that many of these symptoms are likely to be a result of variou forms of bias and to be non pathogenetic [8]. For example, they compared two trials of Hydrogen. The lower quality trial showed $5000 \%$ more symptoms per volunteer.

\section{Published guidance relating to HPTs}

As noted above, some of the early homeopathic researchers were ahead of the curve in the development of research methodology. It was also noted that there was little change in the guidelines to conduct HPT's until recently. During the $20^{\text {th }}$ century, some authors did regret this lack of progress since the early industriousness of Hahnemann and colleagues. Thus, W. Lees Templeton writes in the British Homeopathic Journal in 1949: "Compared with the dominant school, what have we done in 100 years? I am bound to say [...] very little indeed [...] We seem to have done little or nothing to improve the foundations" [27]. He went on to call for a group of researchers to come together to develop HPTs in the way how Hahnemann and colleagues had done originally.

Some authors did recognise that developments in the health sciences and the understanding of human psychology had led to significant progress in the design and conduct of trials with human subjects, and that these might usefully be applied to homeopathic trials. For example, in 1961 Stephenson, writing in the British Homeopathic Journal, suggested various additions to trial methods, which would be "in line with modern experimental technique, e.g the double-blind, random selection, placebo trials in the provers and at least 75 subjects in the whole drug proving experiment" [28].

Reviewing progress in an article for the same journal in 1995 , Belon noted that "since the early $20^{\text {th }}$ century and more especially since World War II, classical pharmacology has systematically applied methods of evaluation which homeopaths cannot ignore" [29].

It was only with the publication of 'The dynamics and methodology of homeopathic provings' by Jeremy Sherr in 1994 that any significant new guidelines appeared that had a real impact on the practice in this area in the English-speaking milieu [30]. This was the first publication in English that was focused entirely on HPTs and has been very influential for the design of many HPTs that have been conducted since then. It has also stimulated more people within the homeopathic community to understand the value and necessity of conducting trials with new substances and retrials of those already included in the homeopathic materia medica. Sherr described a clear methodology to conduct of HPTs. However, it does not address some of the weaknesses identified by Dantas. Notably, he plays down the important role of placebo control as a comparison standard for the active intervention.

\section{Recommendations for future HPTs}

It seems quite possible to develop HPT's which have the rigour and necessary design features of the modern health trials, which can also capture any real pathogenetic effects and distinguish them from background noise. Unfortunately there is a real reluctance on the part of some of those in the homeopathic community who actually conduct HPTs to accept the need for trial designs which will properly reduce bias. At the same time a methodology has yet to emerge which properly deals with an issue of great importance from the point of view of homeopathic practice, namely the issue of recruiting a sufficient number of volunteers susceptible and sensitive to the remedy being tested [31]. 
In a review of HPT's conducted from 1945 to 1995, Dantas et al concluded that the quality of such trials was generally poor, although with a clear trend towards improved quality, with increased use of randomisation and masking, in the last two decades of that period [8]. A recent systematic review that included trials conducted in the decade since then found a reasonable number of high quality HPT's [26]. Whilst the percentage that met the criteria for rigour and quality was very low (3\%), this review found 15 trials which used control groups, random allocation, blinding, and methods for dealing with loss to follow up. However, none of these had any methods for screening volunteers for susceptibility.

Hahnemann was both innovative and rigorous. In the matter of HPTs he developed methods which were innovative for the time, but that from a $21^{\text {st }}$ century perspective have a number of flaws. It remains the case that too few of the HPTs that are undertaken today meet modern standards for quality, and this means in practice that they are likely to overestimate the real pathogenetic effects of remedies, pointing to the real danger of false symptoms appearing in the homeopathic materia medica.

There have now been a number of recommendations made by expert groups in relation to the HPT's, and these continue to be updated. [18, 32,33] Two hundred years after Hahnemann, we should respect the innovation and rigour that he demonstrated by continuing to refine and develop HPT's , to conduct them according to the most rigorous standards and to admit, as he wished to do, only reliable and verified symptoms into the materia medica.

\section{References}

[1] Bradford TL. The life and letters of Samuel Hahnemann. Philadelphia Boericke and Tafel 1895.

[2] Hahnemann S. Translated by Dudgeon R Lesser Writings of Samuel Hahnemann. Reprinted New Delhi B Jain 2005.

[3] Hahnemann S. Translated by Kunzli J Naude A and Pendleton P Organon of Medicine. London Victor Gollancz para 128 p111 1983.

[4] Hahnemann S. Translated by Dudgeon R Materia Medica Pura 1811 - 1821. Liverpool Homeopathic Publishing society, reprinted New Delhi B Jain 1996.

[5] De Marque D. The Development of Proving Methods Since Hahnemann Brit Hom J 1987; 76: 71-75.

[6]. Waisse Priven S. The emergence of modern therapeutic similarity International Journal of High Dilution Research, 2008; 7(22): 21 - 29.

[7] Tischner R. Geschichte der Homöopathie. Leipzig: Willmar Schwabe, 1932-4, volume 2, pp167-8.

[8] Dantas F. How can we get more reliable information from homeopathic pathogenetic trials? A critique of Provings. Brit Hom J 1996; 85: 230-236.

[9] Dudgeon RE. On the Proving of Medicines ,from Lectures on the Theory and Practice of Homeopathy 1853, in Herscu P. Provings Volume 2. An annotated selection of historic and contemporary writings. Amherst New England School of Homeopathy Press, p39; 2002. 
[10] Weatherley JE, Thompson EA, Thomas KJ. The placebo controlled trial as a test of complementary and alternative medicine:observations from research experience of individualised homeopathic treatment Homeopathy 2004; 93 :186-189.

[11] Peters D. Understanding the placebo effect in complementary medicine London Churchill Livingstone 2001.

[12] Rosenthal R, Rosnow R. Artifacts in behavioural research. Oxford Oxford University Press. 2009.

[13] Kaptchuk TJ. When Does Biased Become Unbiased The Dilemma of Homeopathic Provings and Modern Research Methods Brit Hom J October 1996; 85:237-247.

[14] Torgerson DJ, Torgerson CJ. Designing and running randomised trials in health and the social sciences. London Palgrave Macmillan 2008.

[15] Ioannidis J, Haidich AB, Pappa M, Pantazis N, Kokori S, Tektonidou M, Contopoulos-Ioannidis D, Lau J. Comparison of Evidence of Treatment Effects in Randomized and Nonrandomized Studies JAMA. 2001;286:821-830.

[16] Concato J, Shah N, Horwitz, RI. Randomized, controlled trials, observational studies, and the hierarchy of research designs, N Engl J Med 2000;342:1887-1892.

[17] Schulz KF, Chalmers I, Hayes R, Airman DG. Empirical evidence of bias: dimensions of' methodological quality associated with estimates of treatment effects in controlled trials. JAMA 1995;273:408-12.

[18] Dantas F, Fisher P, Walach H, Wieland F, Rastogi DP, Teixeira H, Koster D, Jansen JP, Eizayaga J, Alvarez MEP, Marim M, Belon P, Weckx LLM. A systematic review of the quality of homeopathic pathogenetic trials published from 1945 to 1995 . Homeopathy 2007; 96

[19] Dean ME. The Trials of Homeopathy KVC Verlag Germany 2004

[20] Bellows HP. The Test Drug-Proving of the O. O. \& L. Society: A Reproving of Belladonna Being an Experimental Study of the Pathogenic Action of that Drug Upon the healthy Human Organism. Boston: The O. O. \& L. Society, 1906

[21] De Amici D, Kiersy C, Ramajli F, Brustia L, Politi P. Impact of the Hawthorne effect in a longitudinal Clinical study: The case of anesthesia Controlled Clinical Trials 2000;21:2:103-114

[22] Reidenburg MM, Lowenthal DT. Adverse non drug reactions N Eng J Med,1968; 279: 678-9

[23] Wieland F. (1997) The need for GHP guidelines. A brief survey of recent developments in methodology of homeopathic drug Provings in Europe Brit Hom J,1997; 86 :229-234

[24] Geers AL, Helfer SG, Weiland PE, Kosbab K. Expectations and placebo response: a laboratory investigation into the role of somatic focus. J Behav Med,2006; 29:171-8

[25] Herscu P. Provings Volume 2. An annotated selection of historic and contemporary writings. Amherst New England School of Homeopathy Press p91 2002

[26] Rogers J. A Systematic review of Homeopathic Pathogenetic Trials. University of York. 2009 
[27] Lees Templeton W. Provings Brit Hom J ,1949;39:53-63

[28] Stephenson. Brit Hom J Homeopathic Provings In The Light Of The Newly Formulated "Human Pharmacology", Brit Hom J,1961; 50:129-31

[29] Belon P. Provings Concept and Methodology Brit Hom J,1995; 84:213-217

[30] Sherr J. The dynamics and methodology of Homeopathic Provings Dynamis Books Malvern.1994

[31] Shalts E. A Double Blind Placebo Controlled Pilot Study of the Validity of Provings as a method of Finding Pathogenic Characteristics of Homeopathic Remedies. In Herscu P Provings Volume 2 New England School of Homeopathy Press Amherst MA pp401-417 2002

[32] European Committee for homeopathy Homeopathic drug proving guidelines European Committee for homeopathy Brussels, 2004.

[33] European Council for Classical Homeopathy ECCH Guidelines for Homeopathic Pathogenic Trials Second Edition ECCH Norfolk UK 2007.

\section{Hahnemann e a metodologia de ensaios patogenéticos em voluntários saudáveis: uma reavaliação}

\section{RESUMO}

Este artigo discute as orientações e protocolos desenvolvidos por Hahnemann, para a realização de ensaios homeopáticos patogenésicos e reavalia-os com base no conhecimento e protocolos atuais, usados em pesquisas clínicas envolvendo humanos. Técnicas e métodos inovadores foram introduzidos por Hahnemann objetivando a redução de viéses estatísticos. Alguns aspectos metodológicos que podem induzir viéses em ensaios patogenésicos e que podem levar a inclusão incorreta de sintomas são discutidos. Dentre vários, podemos citar: ausência de grupo controle, ausência de randomização, ausência de protocolo cego, inclusão de sintomas triviais e pré-existentes, inclusão de conhecidos como participantes no estudo e a falta de definição do estado saudável. Recomendações de especialistas e de trabalhos publicados recentemente, relacionados aos ensaios patogenésicos são discutidos. A importância do desenvolvimento de métodos capazes de identificar a susceptibilidade dos participantes, aos medicamentos testados, é discutida. A ausência de ensaios desenhados com alto padrão metodológico é destacada. Este artigo termina com um apelo para que pesquisadores mantenham o mesmo desejo pela inovação e rigor metodológico, como Hahnemann, no desenvolvimento dos ensaios patogenésicos, não obstante atendendo plenamente os protocolos e requerimentos necessários para qualquer ensaio de medicamentos, com humanos, de forma que, como Hahnemann queria, somente sintomas confiáveis possam ser admitidos na matéria medica e na prática clínica.

Palavras-chaves: Homepatia; Ensaios patogenésicos, ensaio clinico fase 1.

\section{Hahnemann y la metodología de ensayos patogenéticos en voluntarios sanos: una reevaluación}

\section{RESUMEN}

Este artículo reevalúa las orientaciones y protocolos que Hahnemann formuló para los ensayos patogenéticos homeopáticos (HPTs) a la luz de conocimientos y protocolos recientes para la investigación en seres humanos. 
Son mencionados algunos aspectos y métodos innovadores formulados por Hahnemann, en particular aquellos destinados a reducir sesgos. Un número de aspectos actualmente conocidos que llevan a sesgos en ensayos y que pueden aparecer en el reporte de síntomas son discutidos en el contexto de los HPTs. Entre estos aspectos se menciona: ausencia de grupos-controle, ausencia de distribución aleatoria, falta de cegamiento, inclusión de síntomas triviales y pre-existentes, inclusión de personas conocidas como participantes del estudio y la falta de definición del concepto de estado de salud. Se discute la opinión de expertos así como la literatura especializada publicada en las últimas décadas sobre el diseño de HPTs. También es abordad la importancia de formular métodos para seleccionar participantes en HPTs en función de su susceptibilidad a la droga estudiada. Es resaltada la falta de estudios de alta calidad metodológica. O artículo concluye con una convocatoria para que los investigadores utilicen el mismo rigor e espíritu innovador que Hahnemann en el desarrollo de HPTs, y que al mismo tiempo reconozcan plenamente los requisitos y protocolos necesarios en cualquier ensayo de drogas en seres humanos de modo a cumplir el desiderátum de Hahnemann: admitir solamente síntomas confiables en la materia médica y la práctica clínica.

Palabras-llave: Homeopatía; Ensayos patogenéticos; Ensayo clínico fase 1

\section{(c)) BY-Nc-ND Licensed to GIRI}

Support: authors declare that this study received no funding.

Conflict of interest: authors declare there is no conflict of interest.

Received: 29 June 2010; Revised: 22 September 2010; Published: 30 September 2010.

Correspondence author: Jim Rogers, jrogers@lincoln.ac.uk, www.lincoln.ac.uk

How to cite this article: Rogers, J. Hahnemann and the methodology of pathogenetic trials in healthy volunteers: a reappraisal. Int $J$ High Dilution Res [online]. 2010 [cited YYYY Month dd]; 9(32):94-103. Available from: http://www.feg.unesp.br/ ojs/index.php/ijhdr/article/view/373/444 . 